\title{
TETRANORTRITERPENOID INSECT ANTIFEEDANTS FROM SEVERINIA BUXIFOLIA
}

\author{
Tian Shung Wu, ${ }^{*}$ Yann li leu, Yu Yi Chan, Pei lin Wu, Chang Sheng Kuoh, $\dagger$ Shwu Jen Wu $\ddagger$ \\ and $Y_{U} W_{A N G S}$
}

Department of Chemistry, Cheng Kung University, Tainan, Taiwan, Republic of China; †Department of Biology, Cheng Kung University, Tainan, Taiwan, Republic of China; †China Junior College of Medical Technology, Tainan, Taiwan, Republic of China; §Department of Chemistry, National Taiwan University, Taipei, Republic of China

(Received in revised form 20 January 1997)

Key Word Index-Severinia buxifolia; Rutaceae; root bark; antifeeding effect; limonoids; severinolide; cycloseverinolide.

\begin{abstract}
Two new tetranortriterpenoids, scverinolide and cyclosevcrinolide, together with four known compounds, were isolated and characterized from the root bark of Severinia buxifolia. Severinolide, atalantin and cycloepiatalantin showed significant antifeeding effects against Plutella xylostalla. (C) 1997 Elsevier Science Ltd. All rights reserved
\end{abstract}

\section{INTRODUCTION}

Severinia buxifolia (Atalantia buxifolia) is a Chinese folk medicine and has been used for treatment of chronic rheumatism, paralysis, snake-bite and malaria [1]. Essential oils, coumarins, acridone alkaloids, sesquiterpenoids and triterpenoids have been isolated from this plant [2-9]. The leaves of this plant show resistance to phytophagous insects and the ethanol extract of the root bark of S. buxifolia was found to show significant antifeedant activity. This led us to reinvestigate its constituents. Bioassay-directed fractionation of the plant extract led to isolation and characterization of severinolide (1a), atalantin (3) and cycloepiatalantin (6) as the antifeedant principles of the chloroform soluble fraction. We now describe the structural elucidation of two new limonoids, severinolide (1a) and cycloseverinolide (2a) together with four known compounds (3-6) which were isolated from the root bark of $S$. buxifolia and their antifeeding activity.

\section{RESULTS AND DISCUSSION}

All of the limonoids except atalantolide (5) isolated in this study showed four $\mathrm{C}$-Me resonances in their ${ }^{1} \mathrm{H}$ NMR spectra instead of five C-Me expected for an obacunone system. This fact suggested that these natural products belong to the limonin series and that $\mathrm{C}-19$ has been oxidized.

Severinolide (1a) was isolated as optically active

* Author to whom correspondence should be addressed. colourless plates and its elemental analysis indicated a molecular formula $\mathrm{C}_{31} \mathrm{H}_{38} \mathrm{O}_{11}$. The signals of $1 \mathrm{a}$ at $\delta$ $165.4(s), 167.3(s), 170.3(s)$ and $170.8(s)$ in the ${ }^{13} \mathrm{C}$ NMR spectrum, together with the IR bands at 1750 , 1735 and $1710 \mathrm{~cm}^{-1}$, revealed the presence of an $\alpha, \beta$ unsaturated ester, $\delta$-lactone and ester groups in the molecule. The ${ }^{1} \mathrm{H}$ NMR spectrum of la showed typical signals $[10,11]$ for a $\beta$-substituted furan ring: $\mathrm{H}-17$, $\mathrm{H}-15$ an $\alpha, \beta$-unsaturated ester system and an $\mathrm{AB}$ quartet for H-19 of a limonoid system as well as four CMe resonances (Table 1). Two singlet acetyl signals appeared at $\delta 2.27$ and 1.98 (each $3 \mathrm{H}$ ). Severinolide (1a) was hydrolysed with sodium hydroxide and then acidified by hydrochloric acid to give $\mathbf{1 b}$. Methylation of 1 b with diazomethane afforded the diol derivative (1c). Oxidation of 1c with Jones' reagent resulted in the formation of yellow crystals, which were identified as dehydroatalantin (4) by comparison of their spectral data and mixed melting points with an authentic specimen [12]. This result suggested that the two acetyl groups were located at C-6 and C-7. This arrangement was also supported by the fact that hydrolysis of 1 a to give diol (1c) results in a downfield shift of the $\mathrm{H}$ 15 resonance and an upfield shift of the H-5, H-6, H7 and $\mathrm{H}-9$ signals (Table 1). An AMX system [ $\delta 2.90$ $(1 \mathrm{H}, d, J=11 \mathrm{~Hz}), 5.11(1 \mathrm{H}, d d, J=3,11 \mathrm{~Hz})$ and $4.89(1 \mathrm{H}, d, J=3 \mathrm{~Hz})]$ was attributed to $\mathrm{H}-5 \alpha$ (axial), $\mathrm{H}-6 \beta$ (axial) and $\mathrm{H}-7 \beta$ (equatorial). Acetylation of $1 \mathrm{c}$ gave 1a $(21 \%)$ and $1 \mathrm{~d}(72 \%)$, consistent with the $\alpha$ (axial)-configuration of the 7-hydroxyl group. The complete structure and relative stereochemistry of $\mathbf{1 a}$ was determined by single crystal X-ray analysis (Fig. 1). Thus severinolide has structure 1a. 




1a $\mathrm{R}=\mathrm{R} 1=\mathrm{Ac}, \mathrm{R} 2=\mathrm{Me}$

1b $\mathrm{R}=\mathrm{R}_{1}=\mathrm{R}_{2}=\mathrm{H}$

Ic $R=R_{1}=H_{1}, R_{2}=M e$

1d $\mathrm{R}=\mathrm{H}, \mathrm{R} 1=\mathrm{Ac}, \mathrm{R}_{2}=\mathrm{Me}$

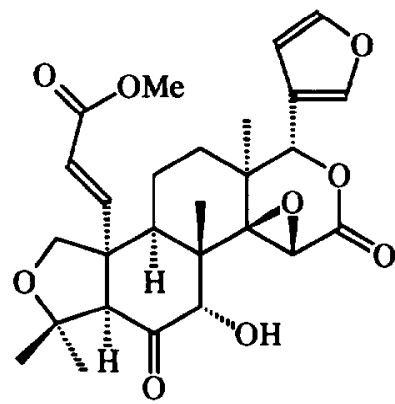

3



4

Cyclosevernolide (2a) was obtained as optically active colourless plates with the molecular formula $\mathrm{C}_{26} \mathrm{H}_{30} \mathrm{O}_{8}$. Its UV spectrum exhibited maxima at 217 and $319 \mathrm{~nm}$ characteristic of the presence of a cyclopentenone system [13]. The IR spectrum of 2a showcd absorption bands at 3530, 3300,1725, 1662, 1030 and $895 \mathrm{~cm}^{-1}$ indicating the presence of two hydroxyl groups, a $\delta$-lactone, an $\alpha, \beta$-unsaturated carbonyl system and a $\beta$-substituted furan ring in the molecule.

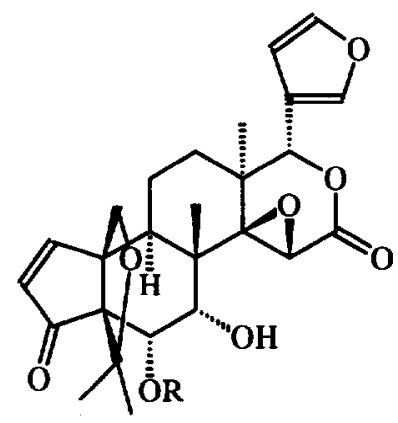

2a R=H

$2 \mathbf{b} \mathbf{R}=\mathrm{Ac}$

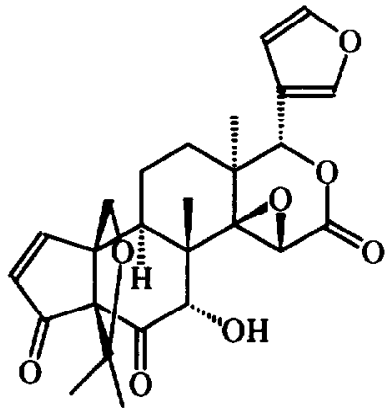

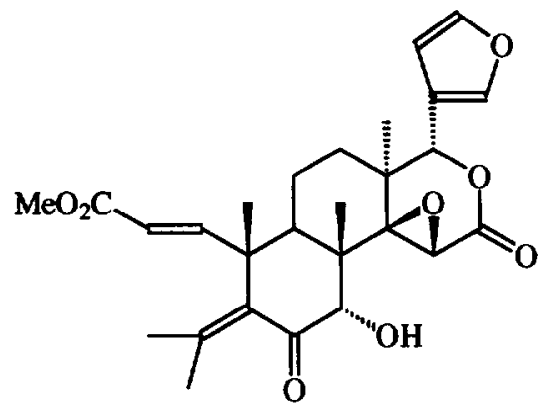

5

The ${ }^{1} \mathrm{H}$ NMR spectrum (Table 1) revealed typical $\mathrm{H}$ 15 and $\mathrm{H}-17$ signals in a $\beta$-substituted furan ring, ring $D$ epoxylactone, an $\alpha, \beta$-unsaturated ketone and two hydroxyl protons (exchanged with $\mathrm{D}_{2} \mathrm{O}$ ). The appearancc of four tertiary methyl signals and an $\mathrm{AB}$ quartet at $\delta 3.79$ and $3.96($ each $1 \mathrm{H}, d, J=9.5 \mathrm{~Hz}$ ) suggested a carbon skeleton related to that of limonin with an ether bridge from $\mathrm{C}-19$ to $\mathrm{C}-4$. The above data suggested that cycloseverinolide (2a) was similar to 
Tetranortriterpenoids from Severinia buxifolia

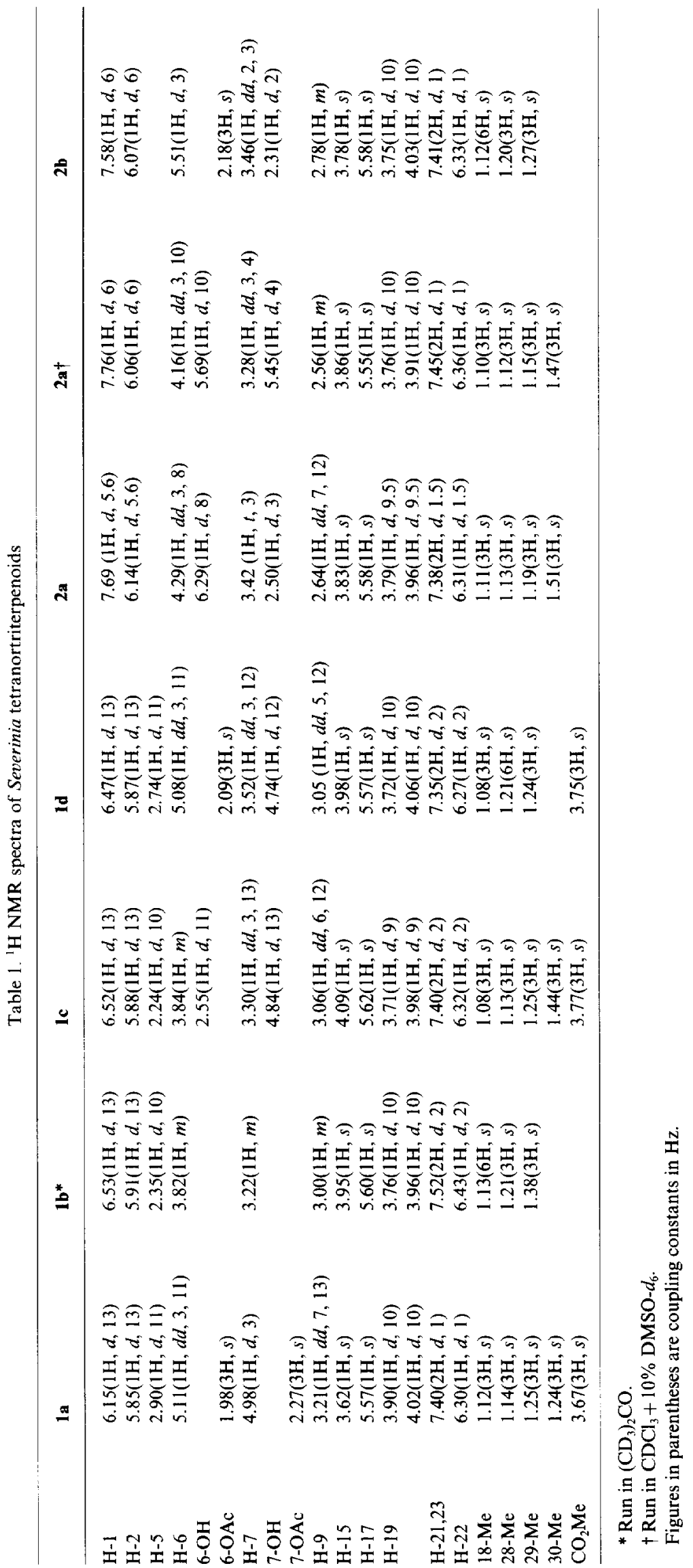




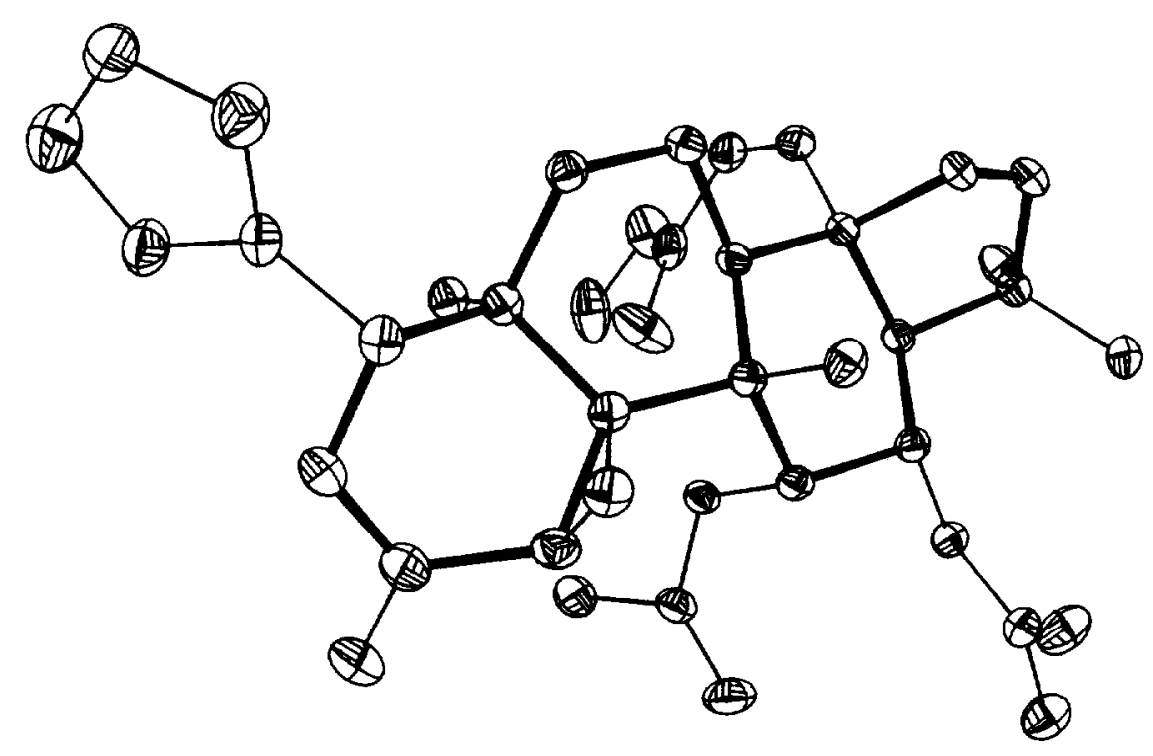

1a

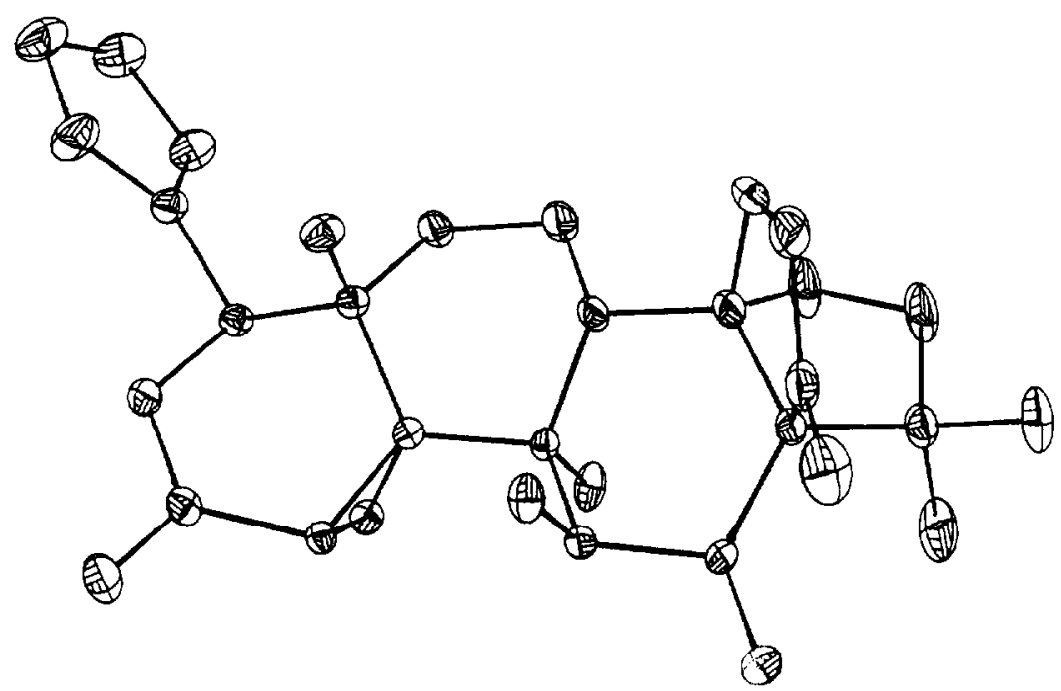

$2 \mathbf{a}$

Fig. 1. Structure and solid-state conformation of compound 1a and $\mathbf{2 a}$.

cycloepiatalantin (6) [14]. Oxidation of 2a with Jones' reagent afforded colourless needles which had identical spectral data and TLC behaviour with an authentic sample of 6 . This indicated that the two hydroxyl groups were located at $\mathrm{C}-6 \alpha$ and $\mathrm{C}-7 \alpha\left[J_{6.7}=3 \mathrm{~Hz}\right]$. The complete structure and relative stereochemistry of $2 a$ was determined by a single crystal $X$-ray analysis (Fig. 1). Thus cycloseverinolide has structure $2 \mathrm{a}$.

The known compounds, atalantin (3) [15], dehydroatalantin (4) [12], atalantolide (5) [16] and cycloepiatalantin (6) [14] were also isolated and characterized by comparison of their spectroscopic data (UV, IR, NMR and mass spectrometry) with literature values.
The isolated compounds were subjected to antifeedant activity evaluation $[17,18]$. Severinolide (1a), atalantin (3) and cycloepiatalantin (6) showed strong antifeedant activity against third instar larvae of the Diamondback moth (Plutella xylostella) with $\mathrm{ED}_{50}$ at concentrations of $0.0625,0.0625$ and $0.25 \%$, respectively (Table 2).

\section{EXPERIMENTAL}

Mps: uncorr. 'HNMR (100, 200, $400 \mathrm{MHz})$ were recorded in $\mathrm{CDCl}_{3}$ except where noted. Chemical shift values are showed in ppm $(\delta)$ with TMS as an int. standard. MS were recorded using a direct inlet 
Table 2. Antifccding activity of tetranortriterpenoids from Severinia buxifolia

\begin{tabular}{|c|c|c|c|c|c|c|c|c|c|c|}
\hline & & & 1 & & & & Tims & $\begin{array}{l}\text { II } \\
\text { e (day) }\end{array}$ & & \\
\hline & thod & & Time (day) & & 1 & & 2 & 2 & 5 & 5 \\
\hline Compd & concn. $(\%)$ & 1 & 2 & 5 & $\mathrm{C}$ & $\mathrm{T}$ & $\mathrm{C}$ & $\mathrm{T}$ & $\mathrm{C}$ & $\mathrm{T}$ \\
\hline 1a & 0.5 & \pm & \pm & \pm & ++++ & \pm & ++++ & \pm & $+t+t$ & + \\
\hline & 0.25 & \pm & \pm & \pm & ++ & \pm & ++++ & \pm & ++++ & + \\
\hline & 0.125 & \pm & \pm & \pm & + & \pm & ++++ & \pm & ++++ & \pm \\
\hline & 0.0625 & + & + & ++ & +++ & \pm & ++++ & ++ & $++t$ & +++ \\
\hline & 0.03125 & + & +++ & +++ & +++ & + & ++++ & +++ & ++++ & ++++ \\
\hline 2a & 0.5 & ++ & +++ & ++++ & + & ++ & ++++ & $+t+t$ & ++++ & ++++ \\
\hline & 0.25 & + & +++ & +++ & + & ++ & $++t+$ & $++t+$ & ++++ & ++++ \\
\hline 3 & 0.5 & \pm & \pm & \pm & +++ & \pm & $t+t+$ & + & ++++ & ++ \\
\hline & 0.25 & \pm & $\overline{ \pm}$ & \pm & ++ & $\overline{ \pm}$ & ++++ & + & ++++ & ++ \\
\hline & 0.125 & \pm & \pm & + & ++ & \pm & $++t+$ & ++ & ++++ & +++ \\
\hline & 0.0625 & \pm & ++ & +++ & +++ & \pm & ++++ & ++ & ++++ & ++++ \\
\hline & 0.03125 & $\bar{t}$ & +++ & ++++ & +++ & \pm & $++t+$ & +++ & ++++ & ++++ \\
\hline 4 & 0.5 & \pm & \pm & + & +++ & \pm & $+t+t$ & ++ & ++++ & +++ \\
\hline 5 & 0.5 & ++ & ++++ & ++++ & +++ & + & ++++ & ++++ & ++++ & $++t+$ \\
\hline & 0.25 & ++ & ++++ & ++++ & ++++ & + & ++++ & ++++ & ++++ & ++++ \\
\hline 6 & 0.5 & \pm & \pm & \pm & +++ & + & ++++ & +++ & ++++ & +11 \\
\hline & 0.25 & \pm & \pm & \pm & ++++ & \pm & ++++ & ++ & ++++ & ++ \\
\hline Galecron & 0.5 & \pm & + & + & +++ & \pm & ++++ & \pm & ++++ & \pm \\
\hline & 0.25 & $\overline{ \pm}$ & + & $t+$ & ++ & \pm & $+t+t$ & +++ & ++++ & ++ \\
\hline & 0.125 & \pm & ++ & +++ & ++ & \pm & $+t+t$ & ++ & $++t+$ & ++ \\
\hline & 0.0625 & \pm & ++ & ++++ & ++ & + & $++t+$ & +++ & ++++ & ++++ \\
\hline & 0.03125 & + & +++ & ++++ & + & \pm & $+t+t$ & ++ & ++++ & ++++ \\
\hline Control & - & ++ & ++++ & ++++ & ++ & 1 & ++++ & 1 & ++++ & i \\
\hline
\end{tabular}

C: no treatment with compound; $T$ : treatment with compound.

Observation: Consumptions of the cabbage leaf disks were evaluated by the index of 6 grades as shown below at 1,2 and 5 days after treatment.

Grades of leaf disk consumption: $-: 0 \% ;+: 1-20 \% ;+: 21-40 \% ;++: 41-60 \% ;+++: 61-80 \% ;++++: 81-100 \%$.

system. UV were determined in $\mathrm{MeOH}$ and IR were recorded in $\mathrm{KBr}$ disc.

Plant material. Severinia buxifolia (Pior.) Tenore was collected from Tainan, Taiwan and identified by Prof. C. S. Kuoh. A voucher specimen is deposited in the Herbarium of the National Cheng Kung University, Tainan, Taiwan, R.O.C.

Extraction and separation. The procedure of extraction and sepn was as related reference [6]. The benzene eluted fr. was rechromatographed on silica gel and eluted with $i-\mathrm{Pr}_{2} \mathrm{O}$ and $\mathrm{Et}_{2} \mathrm{O}$ to afford $1 \mathrm{a}(5.1 \mathrm{~g}), 3$ $(0.61 \mathrm{~g}), 5(0.37 \mathrm{~g}), 4(0.03 \mathrm{~g})$ and a mixt. This mixt. was chromatographed on silica gel using ElOAc-benzene (1:4) as eluent and $20 \mathrm{ml}$ frs were collected and monitored by TLC. The frs giving an identical spot were combined together. Compound $6(0.62 \mathrm{~g})$ and $2 \mathrm{a}(0.57$ g) were obtained, respectively.

Severinolide (1a). Colourless plated $\left(\mathrm{Me}_{2} \mathrm{CO}\right)$, mp $219-221^{\circ} .[\alpha]_{\mathrm{D}}+53.08^{\circ}\left(c 1.3, \mathrm{CHCl}_{3}\right)$. Anal. calcd for $\mathrm{C}_{31} \mathrm{H}_{38} \mathrm{O}_{11}$ : found: $\mathrm{C}, 63.42 ; \mathrm{H}, 6.55 \%$, required: $\mathrm{C}$, $63.48 ; \mathrm{H}, 6.48 \%$. UV $\lambda_{\max } \mathrm{nm}: 214$. IR $v_{\max } \mathrm{cm}^{-1}: 1750$, 1735, 1710, 1640. EIMS $m / z$ (rel. int.): $586[\mathrm{M}]^{+}, 511$, 463, 451, 432, 403, 393, 361, 343, 311, 303, 285, 253, 225, 95(100), 43. ${ }^{13} \mathrm{C}$ NMR (100 $\left.\mathrm{MHz}, \mathrm{CDCl}_{3}\right): \delta$ $170.8(s), 170.3(s), 167.3(s), 165.4(s), 157.3(d), 143.0(d)$, $141.2(d), 120.4(s), 120.2(d), 109.8(d), 82.9(s), 78.0(d)$, $73.2(t), \quad 70.6(d), \quad 69.8(s), \quad 69.2(d), \quad 56.7(d), \quad 54.6(s)$, $51.3(q), \quad 51.1(d), \quad 42.3(s), \quad 38.8(s), \quad 35.4(d), \quad 30.3(q)$, $25.5(t), 23.9(q), 21.0(q), 20.7(q), 18.0(t), \quad 18.0(q)$, 17.1(q).

Hydrolysis of 1a. Compound 1a $(0.5 \mathrm{~g})$ was dissolved in $\mathrm{MeOH}(50 \mathrm{ml})$ containing $\mathrm{NaOH}(2.5 \mathrm{~g})$ and stirred at room temp. for $7 \mathrm{hr}$. The reaction product was treated in the usual way to yield colourless needles of $1 \mathrm{~b}\left(310 \mathrm{mg}\right.$ ) ( $\left.\mathrm{Me}_{2} \mathrm{CO}\right), \mathrm{C}_{26} \mathrm{H}_{32} \mathrm{O}_{9}, \mathrm{mp} 245-247^{\circ}$. IR $v_{\max } \mathrm{cm}^{-1}: 3340,1732,1705,1625$. EIMS $\mathrm{m} / \mathrm{z}$ : $448[\mathrm{M}]^{+}, 452,444,426,422(100 \%), 408,394,380$, $366,210,95$.

Methylation of $\mathbf{1 b}$. Treatment of $\mathbf{1 b}(300 \mathrm{mg})$ with excess $\mathrm{CH}_{2} \mathrm{~N}_{2}$ in the usual way afforded 1c $(290 \mathrm{mg})$ as colourless syrup, $\mathrm{C}_{27} \mathrm{H}_{34} \mathrm{O}_{9}$. IR $v_{\max } \mathrm{cm}^{-1}: 3430$ 1740, 1700, 1625. EIMS $m / z: 469\left([\mathrm{M}]^{+}-43\right), 368$, $361(100), 256,249,236,223,213,185,171,129,121$, $111,97,95$.

Oxidution of 1c. Jones' reagent was added dropwise to stirring soln of $1 \mathrm{c}(0.07 \mathrm{~g})$ in $\mathrm{Me}_{2} \mathrm{CO}$. After standing for $20 \mathrm{~min}$ at room temp., excess of reagent was destroyed by using two drops of MeOH. Standard workup afforded yellowish crystals $(0.053 \mathrm{~g})$ $\left(\mathrm{Me}_{2} \mathrm{CO}\right), \mathrm{mp} 204^{\circ}$, which were identificd as dehydroatalantin (4) by comparison of their spectral data, TLC and mixed mp with authentic sample [12].

Acetylation of $1 \mathrm{c}$. Compound $1 \mathrm{c}(0.15 \mathrm{~g})$ was dissolved in $\mathrm{C}_{5} \mathrm{H}_{5} \mathrm{~N}(2 \mathrm{ml})$ and $\mathrm{Ac}_{2} \mathrm{O}(3 \mathrm{ml})$ and the mixt. 
allowed to stand overnight at room temp. Standard workup gave a residue which showed two spots on TLC (benzene- $\mathrm{Me}_{2} \mathrm{CO}, 4: 1$ ). The mixt. was sepd by prep. TLC using the same solvent system as TLC. The front spot $(32 \mathrm{mg})$ was identified with $\mathbf{1 a}$ by direct comparison. The second spot, compound $1 \mathrm{~d}(107 \mathrm{mg})$, was recrystallized from $\mathrm{Me}_{2} \mathrm{CO}$ as colourless needles, $\mathrm{C}_{29} \mathrm{H}_{36} \mathrm{O}_{10}, \mathrm{mp} 238-240^{\circ}$. UV $\lambda_{\max } \mathrm{nm}: 215$. IR $v_{\max }$ $\mathrm{cm}^{-1}: 3450,1740,1720,1695,1620$. EIMS $m / z$ : $544[\mathrm{M}]^{+}, 513,511,469,451,421,403(100 \%), 361$, $345,343,303,285,253,225,95$.

Crystal data of $1 \mathrm{a} . \mathrm{M}=586$, triclinic, space group P2 $a=18.6659(73), h=13.1231(35), c=11.9066(28)$ $\AA, \alpha=\beta=\gamma=92.909(3)^{\circ}, U=2912.84 \AA^{3}, Z=4$, $D_{\mathrm{c}}=1.336 \mathrm{mg} \mathrm{m}^{-3}, \mu$ (MoK $\alpha$ radiation, $\lambda=0.70923$ $\AA$ ) crystal dimensions: $0.1 \times 0.2 \times 0.3 \mathrm{~mm}$. Intensity data $\left( \pm h, \pm k, \pm l, \theta_{\max }=67^{\circ}\right)$ were recorded on a Siemens $R 3 \mathrm{~m} / \mathrm{V}$ diffractometer. The crystal structure was solved by a direct method. Full-matrix least-squares refinement of atomic parameters (anisotropic $\mathrm{C}$, $\mathrm{O}$; isotropic $\mathrm{H})$ converged at $R=5.10\left(R_{w}=6.33\right)$ over 5753 reflections with $1>3.0 \sigma(1)$.

Cycloseverinolide (2a). Colourless plates $\left(\mathrm{Me}_{2} \mathrm{CO}\right)$, $\mathrm{mp}>360^{\circ} \cdot[\alpha]_{\mathrm{D}}+50.75^{\circ}$ (c $\left.0.4, \mathrm{CHCl}_{3}\right)$. Anal. calcd for $\mathrm{C}_{26} \mathrm{H}_{30} \mathrm{O}_{8}$ : found: $\mathrm{C}, 66.29 ; \mathrm{H}, 6.55 \%$, required: $\mathrm{C}$, $66.37 ; \mathrm{H}, 6.43 \%$. UV $i_{\max } \mathrm{nm}: 217,319$. IR $v_{\max } \mathrm{cm}^{-1}$ : $3530,3300,1725,1662,1590$. EIMS $m / z: 470[\mathrm{M}]^{+}$, $455,329(100 \%), 271,123,121,107,105,95$.

Oxidation of $\mathbf{2 a}$. Compound $2 \mathrm{a}(0.1 \mathrm{~g})$ was oxidized as above to give a colourless needle $(0.075 \mathrm{~g})\left(\mathrm{Me}_{2} \mathrm{CO}\right)$, mp 325-328 (dec.). Anal. calcd for $\mathrm{C}_{26} \mathrm{H}_{28} \mathrm{O}_{8}$ : found: C, $66.29 ; \mathrm{H}, 6.11 \%$, required: $\mathrm{C}, 66.65, \mathrm{H} ; 6.02 \%$. UV $\lambda_{\text {max }} \mathrm{nm}: 215,327$. IR $v_{\max } \mathrm{cm}^{-1}: 3480,1725,1715$, $1690,1590 .[\alpha]_{\mathrm{D}}-77.02^{\circ}\left(c 0.47, \mathrm{CHCl}_{3}\right)$. EIMS $m / z$ : $468[\mathrm{M}]^{+}, 456,422,345,327(100 \%), 287,269,121,95$, 91, identical with cycloepiatalantin (6) [13].

Acetylation of $2 \mathrm{a}$. Compound $2 \mathrm{a}(50 \mathrm{mg})$ was heated in $\mathrm{Ac}_{2} \mathrm{O}(10 \mathrm{ml})$ and pyridine $(2 \mathrm{ml})$ at $105^{\circ}$ for $7 \mathrm{hr}$ The usual workup gave rectangular prisms of $\mathbf{2 b}$ (45 $\mathrm{mg})\left(\mathrm{Me}_{2} \mathrm{CO}\right), \mathrm{C}_{28} \mathrm{H}_{32} \mathrm{O}_{9}$, mp 298-300. UV $i_{\max } \mathrm{nm}$ : $219,326.1 \mathrm{R} v_{\max } \mathrm{cm}^{-1}: 3340,1730,1720,1690,1605$. EIMS $m / z: 512[\mathrm{M}]^{+}, 497,389,371,329,313$, $271(100 \%), 95$.

Crystal data of 2a. $\mathbf{M}=470$, triclinic space group $\mathrm{P} 2, \quad a=11.3099(17), \quad b=11.7209(17), \quad c=$ $16.9764(28) \AA, \alpha=\beta=\gamma=90(3)^{\circ}, U=2250.43 \AA^{3}$, $Z=4, D_{\mathrm{c}}=1.39 \mathrm{mg} \mathrm{m}^{-3}, \mu$ (MoK $\alpha$ radiation, $\lambda=0.70923 \AA)$ crystal dimensions: $0.1 \times 0.2 \times 0.3 \mathrm{~mm}$ Intensity data $\left( \pm h, \pm k, \pm l, \theta_{\max }=70^{\circ}\right)$ were recorded on a Siemens $\mathrm{R} 3 \mathrm{~m} / \mathrm{V}$ diffractometer. The crystal structure was solved by a direct method. Fullmatrix least-squares refinement of atomic parameters (anisotropic $\mathrm{C}, \mathrm{O}$; isotropic $\mathrm{H}$ ) converged at $R=5.53$ $\left(R_{u}=4.07\right)$ over 3490 reflections with $1>3.0 \sigma(1)$.

Antifeeding activity test. The test insect was third instar larvae of Diamondback moth (Plutella xylostella). (a) A filter paper moistened with $1 \mathrm{ml}$ of $\mathrm{H}_{2} \mathrm{O}$ was placed in each Petri dish $(2 \mathrm{~cm}(\mathrm{H}) \times 9 \mathrm{~cm}(\mathrm{D}))$. (b) . Both sides of cabbage leaf disks ( $2 \mathrm{~cm}$ diameter) were treated with $20 \mu \mathrm{l} \mathrm{MeOH}$ of chemicals and air dried, then these were placed on the filter paper. Method I: 4 treated disks were placed in a dish. Method II: 3 treated disks and 3 untreated disks were placed alternately. (c) In method I and II, two larvae per disk were released in a dish.

Acknowledgements-The author is grateful for financial support from the National Science Council of R.O.C. (NSC-87-2113-M-006-). We thank Dr R. D. Bennett (Fruit and Vegetable Chemistry laboratory, Agricultural Research Service U.S. Department of Agriculture) for authentic samples and NMR spectra. We also thank Drs I. Fujimoto and N. Ohno (Pesticides Research Laboratory, Sumitomo Chemical Company, Ltd., Japan) for antifeedant test.

\section{REFERENCES}

1. Sasaki, S., Khoyo Taiwan Minkan Yakuyo Shokubutsu Shi. Khobunkan, Taipei, 1924, p. 36.

2. Scora, R. W., Phytochemistry, 1966, 5, 823.

3. Tin-Wa, M., Scora, R. W. and Kumanoto, J., Lloydia, 1972, 35, 183.

4. Tin-Wa, M., Bonomo, S. and Scora, R. W., Planta Medica, 1979, 37, 379.

5. Dreyer, D. L., Tetrahedron, 1967, 23, 4613.

6. Wu, T. S., Kuoh, C. S. and Furukawa, H., Phytochemistry, 1982, 21, 1771.

7. Wu, T. S., Niwa, M. and Furukawa, H., Phytochemistry, 1984, 23, 595.

8. Gu, G. M., Yaoxue Xuebao, 1987, 22, 886.

9. Qin, D. K., Yaoxue Xuebao, 1986, 21, 683.

10. Dreyer, D. L., Tetrahedron, 1965, 21, 75.

11. Powell, J. W., Journal of the Chemical Society, $1969,47,2849$.

12. Thakar, M. R. and Sabata, B. K., Industrial Journal of Chemistry, 1969, 7, 870.

13. Pasto, D. J. and Johnson, C. R., in Organic Structure Determination. Prentice-Hall, New Jersey, 1969, p. 96.

14. Dreyer, D. L., Bennett, R. D. and Basa, S. C., Tetrahedron, 1976, 32, 2376.

15. Basu, D. and Basu, S. C., Journal of Organic Chemistry, 1972, 37, 3035.

16. Shringarpure, J. D. and Sabata, B. K., Industrial Journal of Chemistry, 1975, 13, 24.

17. Kubo, I. and Klocke, J. A., Les Colloques de II N.R.A. No, 1981, 7, 117.

18. Klocke, J. A. and Kubo, I., Entomology, Experimental and Applied, 1982, 32, 299. 